Journal Port Science Research Vol:2, No:2, 2019

$\overline{\mathrm{PAPER}} \cdot$ Full original article online Free

\title{
Emotional education of the child in Islam
}

\author{
Acer Moqbel Mohammed
}

Directorate of Baghdad Education Karkh III, Ministry of Education, Baghdad, Iraq

Ayser.m78@gmail.com

التربية الوجدانية للطفل في الإسعلام

وزارة التربية، مديرية تربية بغداد الكرج الثالثة، بغداد، العراق مقبل مقدم

Ayser.m78@gmail.com

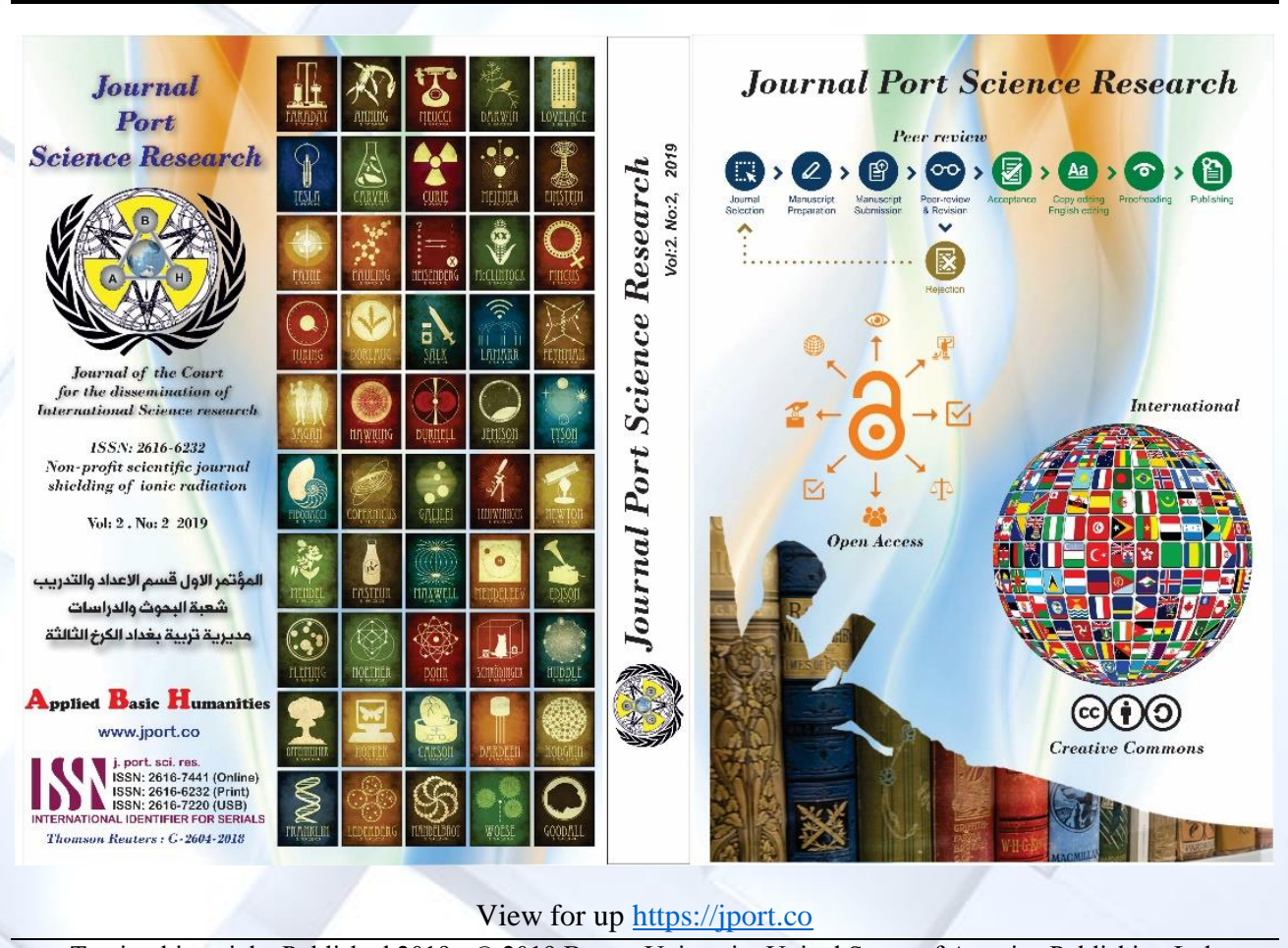

To cite this article: Published 2019 • (C) 2019 Bryant University United States of America Publishing Ltd. 
Ministry of Education Iraqi Directorate of Education Baghdad Karkh III

First Conference Department of Preparation and Training Division of Research and Studies

وزارة التربية العراقية مليرية تريية بغداد الكرخ الثالثة المؤتمر الاول قسم الاعداد والتلدريب ثعبة البحوث واللدراسات

\title{
Emotional education of the child in Islam
}

\author{
Acer Moqbel Mohammed \\ Directorate of Baghdad Education Karkh III, Ministry of Education, Baghdad, Iraq \\ Ayser.m78@gmail.com
}

\begin{abstract}
The main objective of this research is to identify the emotional education and its importance for the child in Islam. There is no doubt that emotional education is an important aspect of Islamic education is not less important than other aspects, and it is important to take this aspect into account, because neglect this aspect and not pay attention The researcher used the descriptive approach as one of the most widely used methods in educational research because it is related to both human and educational phenomena.
\end{abstract}

Keywords: Emotional, Child, Islam.

\section{التربية الوجدانية للطفل في الإسلام}

\author{
أيسر مقبل محمد \\ وزارة التربية، مديرية تربية بغداد الكرج الثالثة، بغداد، العراق \\ Ayser.m78@gmail.com
}

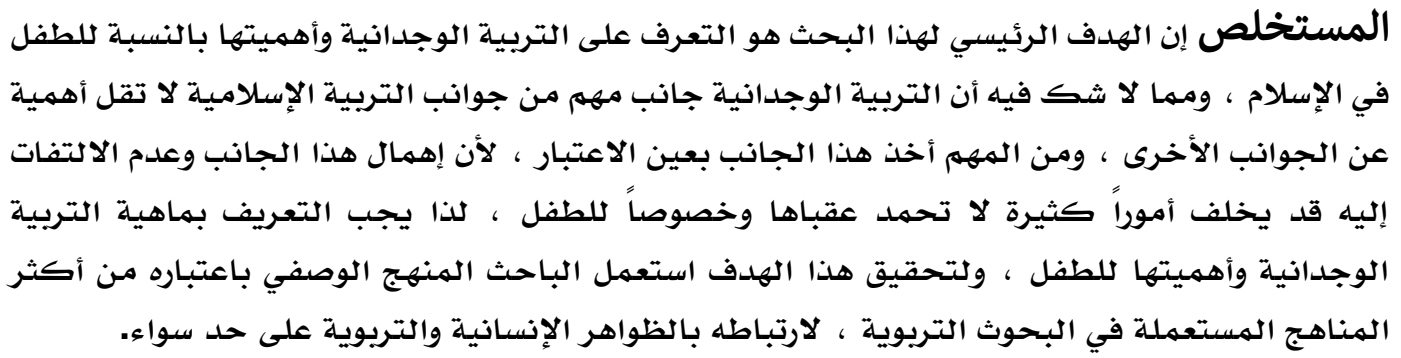


لقد اقر الدين الإسلامي لكافة جوانب الإنسان العقلية والروحية والجسمية والأخلاقية لاسيما الوجدانية منها والعاطفية، ذلك كون الوجدان صفة مهم في الإنسان على كل اشكاله يمكن أن ينمى بالتربية وهن

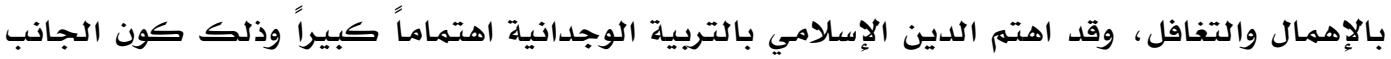
الوجداني يؤثر في سلوك الفرد تجاه نفسه وكل المحيطين به من أفراد أسرته ومجتمعهه ، والعناية به الإنها

تضمن خلو الفرد والمجتمع من الأمراض والاضطرابات النفسية. [1] من الملاحظ أن هناك خلالا واضحاً من قبل المؤسسات التربوية والتعليمية في العناية الكاملة والصحيحة

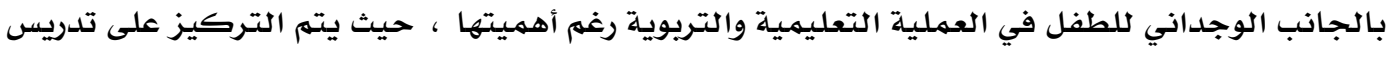
المقررات الدراسية دون الاهتمام بتنمية الجانب الوجداني في نفوس الطلاب ، فهله المقررات مركزة حول

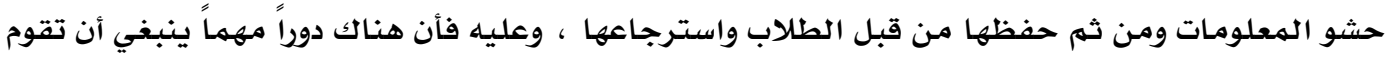
به المؤسسات التريوية في غرس المبادئ والقيم الوجدانية للطفل لتترجهم في سلوكياته خلال ممارسته لمختلف الأنشطة ، فضلاً عن المهمة التي تقوم بها في مراعاة الفطرة وتلبية الحاجات الوجدانية له ـ.

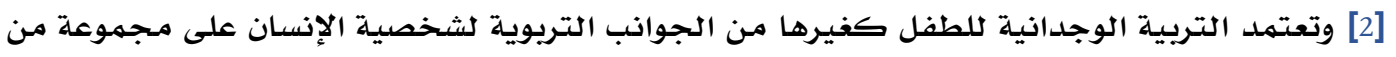

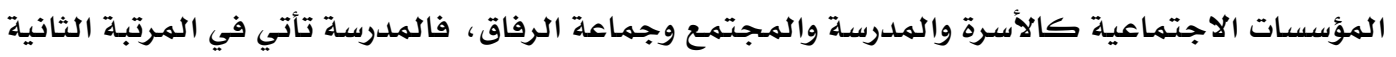

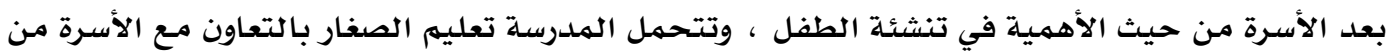
أجل توسيع مدارك الطفل وجعله يحب المعرفة والتعليه ، مما أدى إلى بروز المدرسة كمؤسسة ترئية مهمة ، لها أثرها الفاعل في تربية مختلف جوانب الطفل النفسية والاجتماعية والأخلاقية ، والسلكية ،

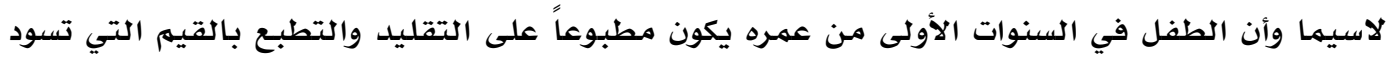

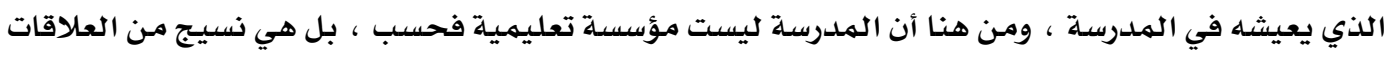
خاصة للطفل الصغير ، ففيها تتوسع الدائرة الاجتماعية للطفل بأطفال جدد وجماعات جديدة ، فيتعلم منها المزيد من المعايير الاجتماعية في شكل منظم ، فهو يتعلم الحقوق والواجبات ، وضبط الانفعالات

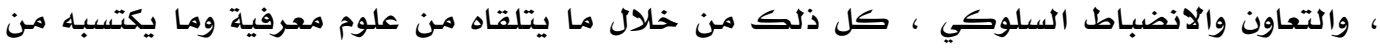

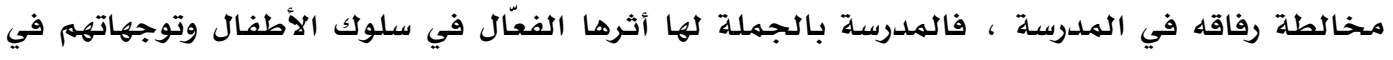
المستقبل لذا يرى الباحث أن من الضروري على الآباء والمربين والقائمين على المؤسسات التربوية أن

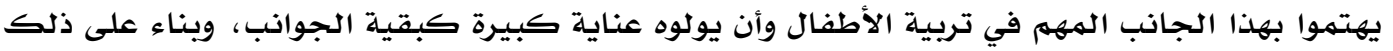

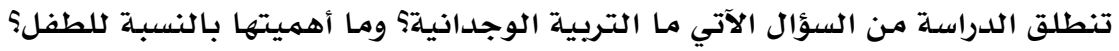

\section{أهمية البحث}

لقد جاء الدين الإسلامي بصورة شاملة ومتكاملة ليكون دين هداية وطمأنينة ورشد ، مخلصاً البشرية من البها الجاهلية المقيتة وما كان فيها من المعتقدات الفاسدة ، ومطهراً نفوسهم ووجدانهم مما علق بها من رذائل الجهل ، وواضعاً أسساً مبادئ وقواعد سليمة للسلوك الإنساني ومقاييس العمل لتحقيق السعادة

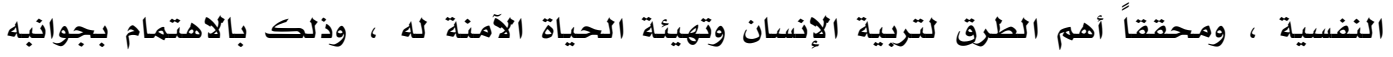
الوجدانية ، ومن أبرز شواهد هذا الدين الرياني العظيم أنه عندما أراد أن يقيم مجتمعه بدأ بتحرير

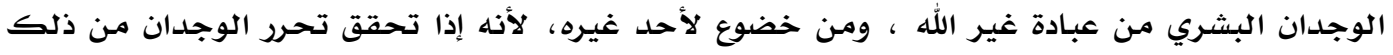

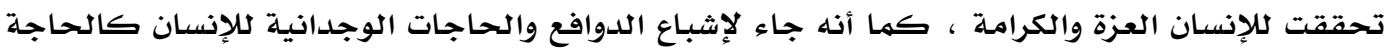
محمد، ، أيسر مقبل. (2019). التربية الوجدانية للطفل في الإسلام. Journal Port Science Research، 2 (2) ، 247- 
إلى الأمن والانتماء والتدين ، وتربية الوازع الديني لدى الفرد وتربيتهُ على الفضائل والمشاعر النبيلة كالصدق والأمانة والتسـامح وسلامسة الصدر من الأحقاد ، والطاعة والإخلاص ، والشعور بالأمل والتفاؤل ، والقناعة والعزة والكرامـة ، فضلاً عن كون الجانب الوجداني أو الانفعالي للشخصية الإنسانية يشتهل على العواطف والمشاعر كالحبر والغضب والخوف والسرور ، والتربية الإسلامية تربية روحية وجسمية واجتماعية وعقلية ، كما أنها تربية وجدانية لأنها تخاطب عاطفة الإنسان وتحثه على العديد من الفضائل

$$
\text { ومكارم الأخلاق • [3، ص94]. }
$$

وحيث أن العاطفة تشكل مساحة واسعة في نفس الطفل الناشئ ، حيث تكون نفسه وتبني شخصيته ، فإن أخذها بشكل متوازن كان إنساناً سوياً في مستقبله وفي حياته كلها ، وإن أخذها بغير ذلك تشكلت لديه

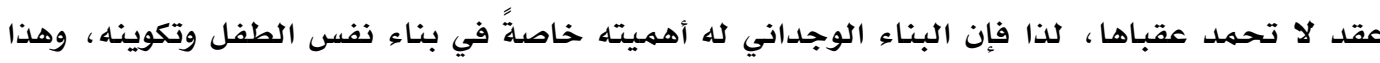
البناء يلعب فيه الوالدان الدور الأكبر، إذ هما الهصدر الأسـاس لأثعة الوجدان والعاطفة ونعمة الأبوة

$$
\text { والأمومسة، وكذلك نعمة الأخوة داخل الأسرة. }
$$
مما تقم يمكن تلخيص أهمية البحث في النقاط الآتية:

1) إن الإسلام اهتم بالجانب الوجداني كفيره من الجوانب، حيث يسعى إلى تكوين الشخصية

$$
\text { المتتكاملة للفرد. }
$$

2) إن مرحلة الطفولة من أهم مراحل حياة الفرد وبالتالي إن الاهتمام بالتربية الوجدانية كجانب

$$
\text { من جوانب تكوين الشخصية الإنسانية أمر ضروري في هذه المرحلة. }
$$

3) إن الهعله بحاجة إلى تعريفه أهمية التربية الوجدانية في العملية التربوية وآليات تفعيلها

$$
\text { وأساليب تنميتها لدى الطلاب، فيعمل على ذلك. }
$$

4) إسهام هذه الدراسـة في إعادة النظر في محتوى المقررات الدراسية ، وكذلك في طرائق التدريس

$$
\text { هدف البحتبعة. }
$$

يهدف البحث إلى بيان التربية الوجدانية للطفل في الإسلام

$$
\text { منهج البحثث }
$$

يتبع الباحث في هذه الدراسـة المنهج الوصفي كونه يلائم إجراءات البحث باعتباره يعتمد على دراسة الواقع أو الظاهرة كما توجد في الواقع ويهتم بوصفها وصفاً دقيقاً.

$$
\text { حلدود الببحث }
$$

أ- حدود موضوعية: التربية الوجدانية المتعلقة بالطفل في الإسلام وأهميتها وذلك من منظور

$$
\text { إسلامي انطلاقاً من القران والسنة النبوية. }
$$

ب- حلدود بشرية: مرحلة الطفولة التي تعد من أهم مـراحل حياة الإنسـان. 
التربية الوجدانية: ويقصد بها الباحث مجموعة العمليات التي تهتم بتنمية الجوانب الوجدانية لدى الفرد

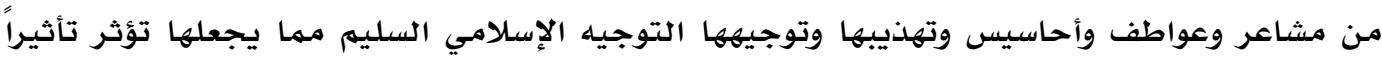
إيجابيا على سلوك ذلك الفرد.

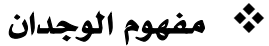

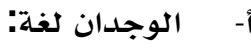

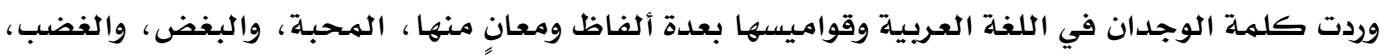

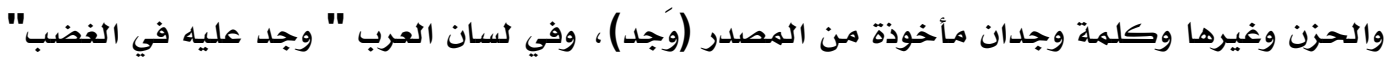

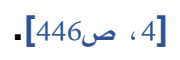

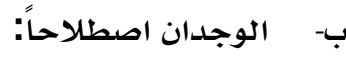
تعددت تعريفات الوجدان عند أهل التربية فيعرف الوجدان بأنه: كلمهة تشمل جميع الأحوال النفسية التي

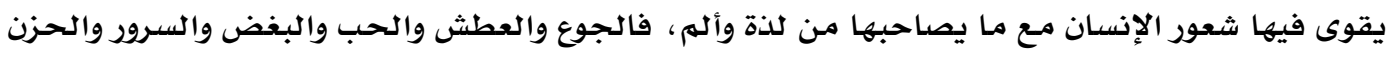

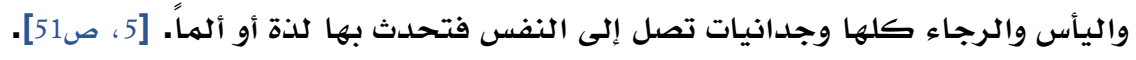

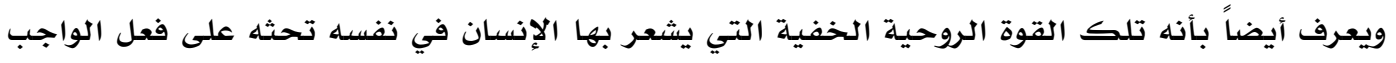

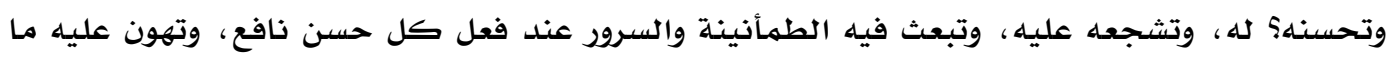

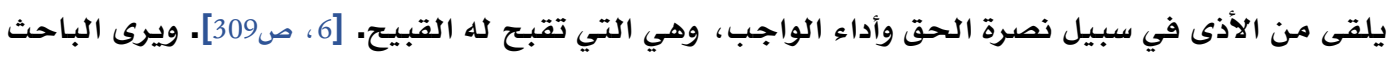

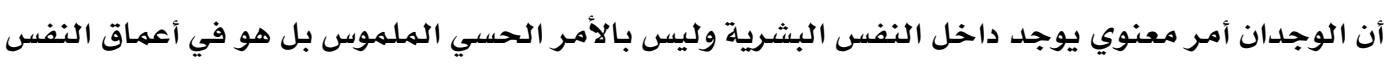

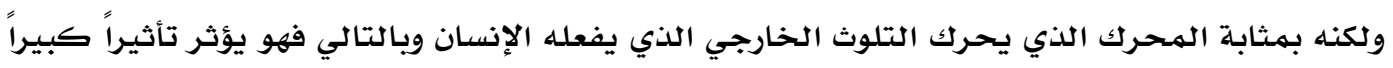
على سلوك الإنسان.

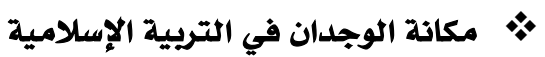

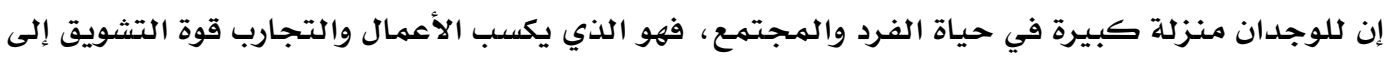

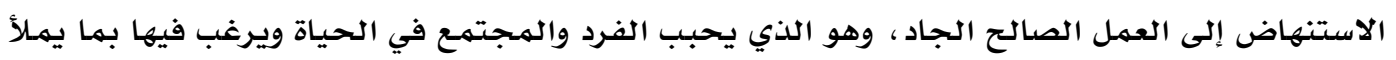

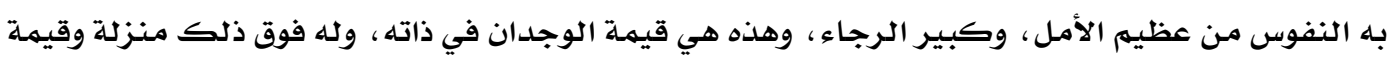

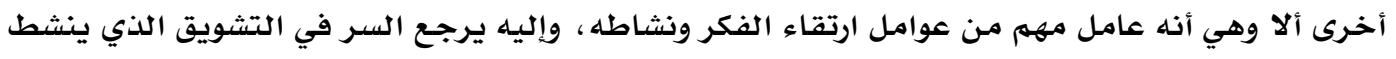

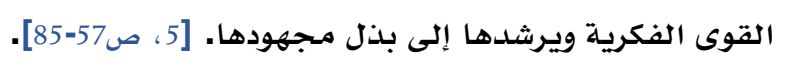

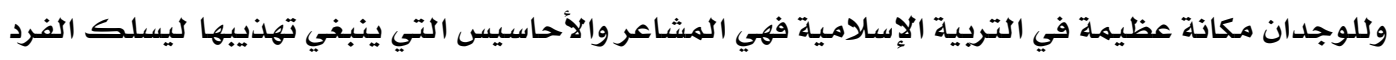

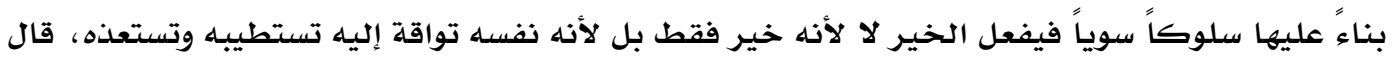

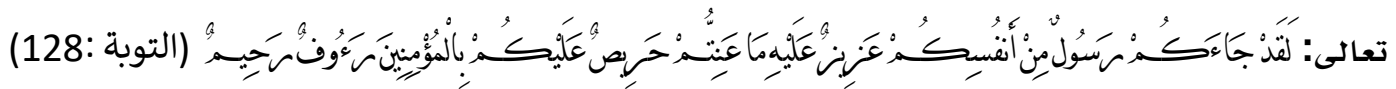

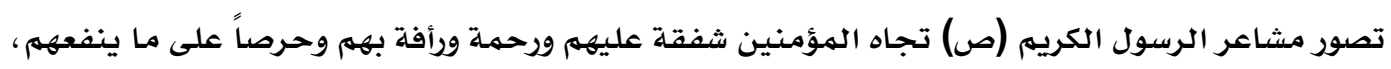
وهذا هو النموذخ الرفيع لما يجب أن يكون عليه المسلهم وجداناً وخلقاً.

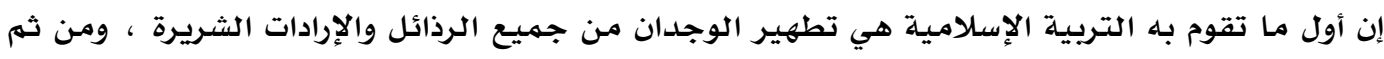

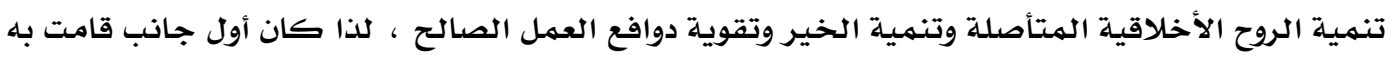

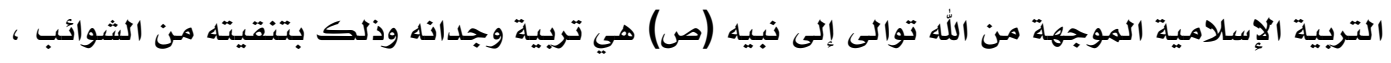

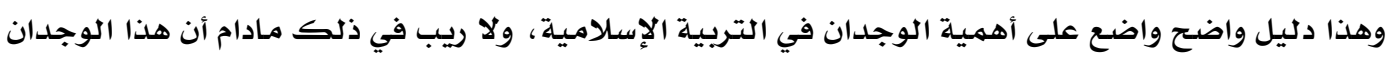


هو المحرك الأساسي للسلوك الإنساني ، والتربية الإسلامية من أهم أهدافها بل هو الهدف الأساسي من أهدافها أن ينشأ الإنسان نشأة صالحة والتي بدورها تضمن له حياة كريمة سوية مليئة بطاعة الله تعالى الإنى

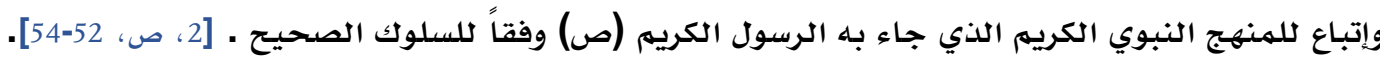

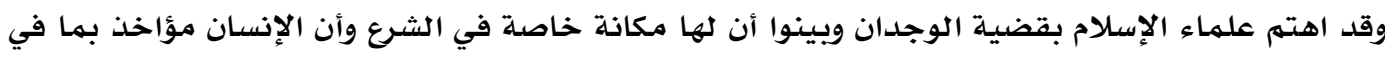

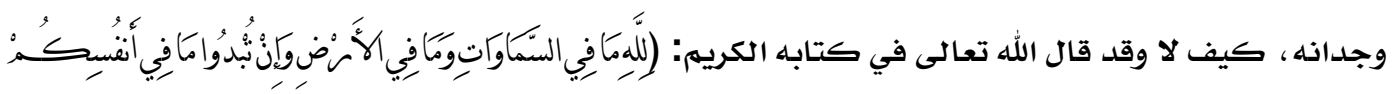

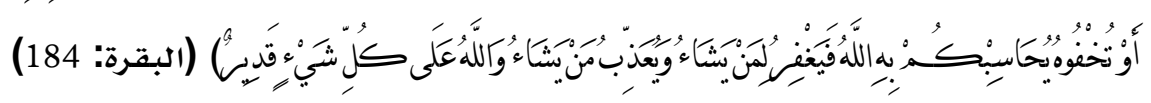
•.مفهوم التربية الوجدانية ومصادرها وأهميتها للطفل

تعرف التربية الوجدانية بأنها: التربية التي تسعى إلى تجنب الضمير التير عثرات الشك والحيرة والضلال

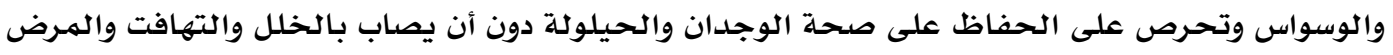
والإجرام ليمسي المرء سيد نفسه ويبدع ضروب سلوكه الأخلاقي لا بإتباع العادة والتقاليد الزائفة ولا

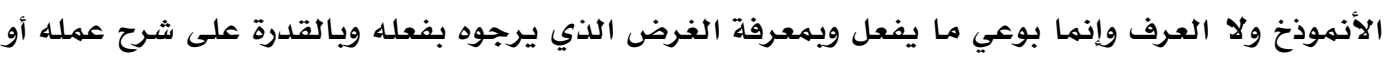

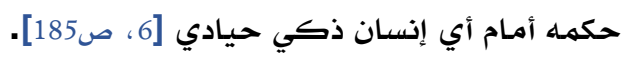

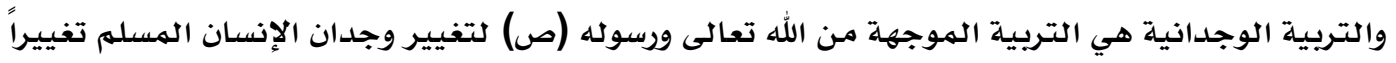

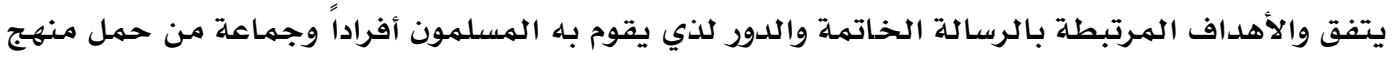

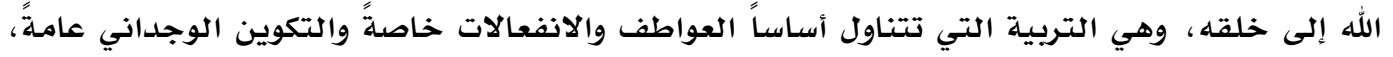

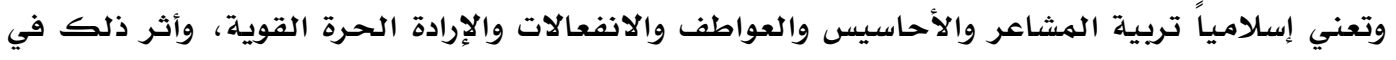

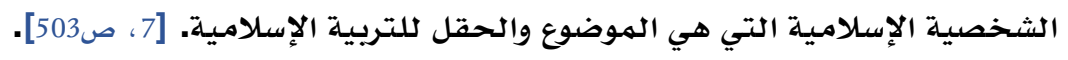

ب- مصادر التربية الوجدانية

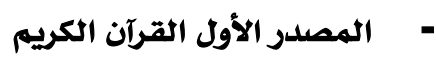

القرآن الكريم هو " كلام الله تعالى المنزل على نبينا محمد(ص) المكتوب في المصاحف، المنقول المبرل نقلاً

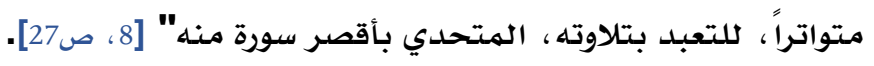

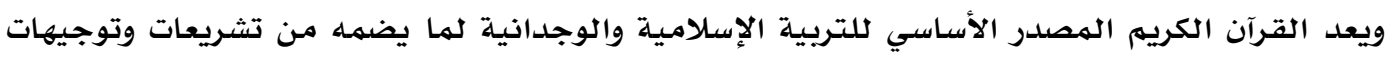

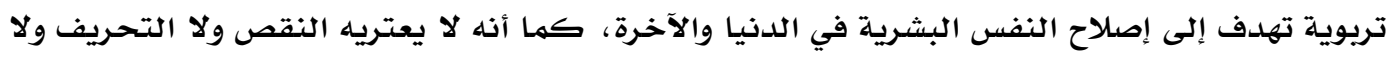

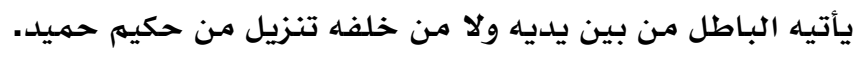

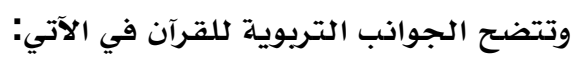

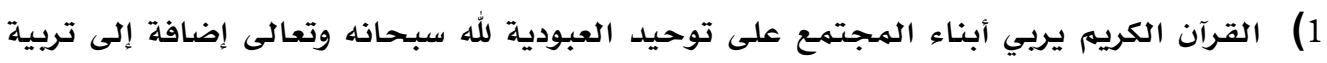

$$
\text { القدرات العقلية على التفكير والتدبر. }
$$

2) القرآن الكريم يربي السلوك الإنساني على الاستقامة وفق شريعة الله سبحانه وتعالى (فَسَتْنِمْ 
مما سبق يتضح أن القرآن الكريم هو المصدر الأساسي والنبع المتكامل في التربية الإسلامية لاسيما في الجانب الوجداني للإنسان، فقد حوى منهجاً متكاملاً عن جوانب الإنسان وصلاته بالله والكان الكون والحياة.

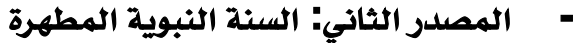

إن السنة النبوية في المجال التربوي فائدتان هما:

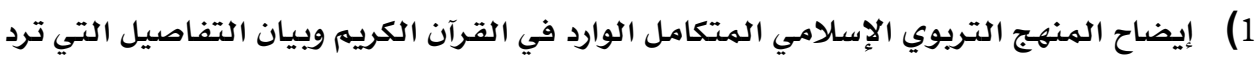

$$
\text { في القرآن الكريم. }
$$

2) استنباط أسلوب تربوي من حياة الرسول (ص) مع أصحابه، ومعاملته الأولاد، وغرس الإيمان

$$
\text { في النفوس [9، ص23-25]. }
$$

لا شك أن الطفل كائن بشري يتأثر كبقية الكائنات، ولديه جملة من الوجدانيات التي تتوزع حسب

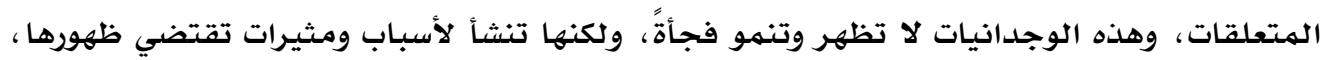

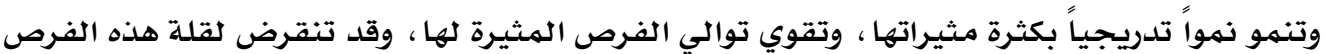

$$
\text { أو لعدمها. [10، ص221] }
$$

ووجدان الطفل يؤثر تأثيراً بالغاً على سلوكه، فما كانت محبة الأطفال لرسول الله (ص) إلا من الن

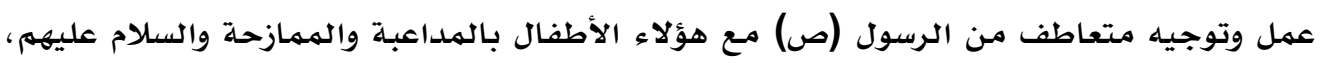
كل هذه الفعال ترعرعت في نفوس الأطفال حتى صارت عاطفة ثابتة في نفوسهـ تثير انفعالاتهم

إن الحاجات البيولوجية والحيوية للطفل كالطعام والشراب وغيرها ضرورية بالنسبة له ، ولكن هناك أيضاً حاجات نفسية ووجدانية ونفسية لا تقل أهمية عنها ، بل أن لها أهمية كبرى في تحقيق تكيف الطفل وتمتعه بالثقة النفسية والعقلية ، وهذه الحاجات الوجدانية من العواطف والأحاسيس يسعى

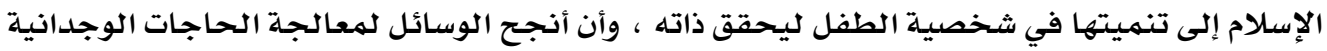

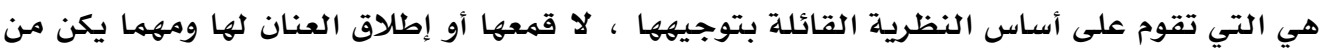
أمر فمادامت هذه الحاجات هي المحركات الرئيسية للسلوك ، فلا بد للمعلم من أن يتفهمها ويعرف كيف يستعين بها على تربية المتعلم تربية حسنة ، ومن أمثلة هذه الحاجات : الحاجة إلى المحبة ، والحاجة إلى الطمأنينة ، والحاجة إلى الانتماء.

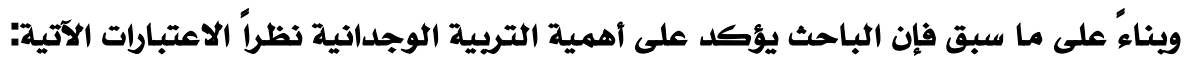
1) أنها تعمل على إشباع حاجات الطفل الوجدانية، مما يجعل تربية الطفل تربية متوازنة شاملة

\section{ومتكاملة.}

2) أنها تعمل على تنمية شخصية الطفل لتحقيق ذاته. 3) ها تعمل على تحقيق التوافق الشخصي للطفل.

4) أنها تعمل على تحقيق تكيف الطفل وتمتعه بالصحة النفسية والعقلية. 5) أنها تؤثر تأثيراً بالغاً على سلوكيات الطفل تصرفاته.

محمدد، أيسر مقبل. (2019). التربية الوجدانية للطفل في الإسلام. Journal Port Science Research، 2(2) ، 247- 
6) أنها تعمل على تهذيب وتوجيه الحاجات بوسطية واعتدال دون إفراط ولا تفريط. • أهداف التربية الوجدانية للطفل ومؤسساتها التربوية:

أ- أهداف التربية الوجدانية للطفل:

تسعى التربية الوجدانية للطفل المنبثقة من الشريعة الإسلامية التي تحقيق مجموعة أهداف، وبناء

\section{ملى ما تقدم يمكن إدراجها بالآتي:}

1) تحرير الوجدان البشري من عبادة أحد غير الله ومن الخضوع لأحد سواه، مما يحقق للإنسان

$$
\text { العزة والكرامة في الدنيا والآخرة. }
$$

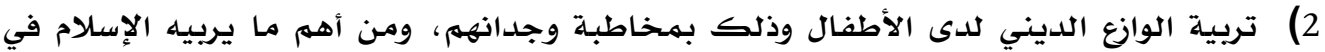

الإنسان الضمير الذي يتكون نتيجة لتمكن المسلم من العقيدة وممارسته المستمرة لها.

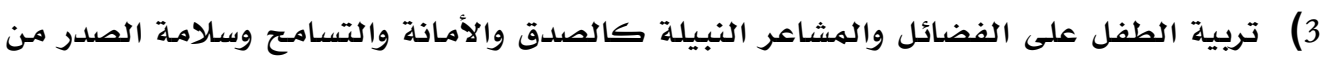
الأحقاد والشعور بالأمل والتفاؤل. 4) نمو الطفل نمواً سليماً خالياً من التغييرات والمشكلات النفسانية والاضطرابات السلوكية وسوء واءول

$$
\text { التكيف مع البيئة. }
$$

5) إشباع الدوافع والحاجات الوجدانية لدى الأطفال كالحاجة إلى الحب والأمن والانتماء عن طريق

$$
\text { تلبية هذه الحاجات وتوفيرها. }
$$

6) ضبط الانفعالات والعواطف والمشاعر لدى الأطفال بما يتوافق ويتلاءم مع تعاليم الدين الدئ

$$
\text { الإسلامي. }
$$

7) تنمية شخصية الطفل التنمية السليمة لتحقيق ذاته والتي تؤدي بدورها إلى ثقته بنفسه وآرائه.

8) تحقيق التوافق الشخصي للطفل وتكيفه وتمتعه بالصحة النفسية والعقلية.

9) تهذيب وتوجيه الحاجات الوجدانية للطفل بوسطية واعتدال دون إفراط ولا تفريط.

\section{ب- أهم مؤسسات التربية الوجدانية للطفل (1 ) - (الأسرة}

إن الإيمان بالله المتولد في الأعماق البشرية عن معرفة صادقة بالله وعن محبته وتقواه هو الأساس التربوي

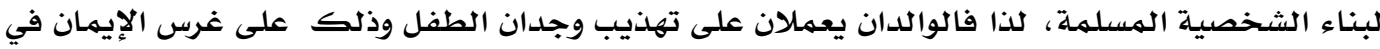
أعماق النفوس الصغيرة الخالية من مفاتن الدنيا وزخارفها ، ولذلك لحماية جوارحهم المفطورة على لهاءلى التوحيد الخالص لله تعالى ، والأبوان مطالبان بتثبيت هذه الفطرة وصيانتها من الضلال والانحراف، لذا فأن قلب الطفل إذا تفتح على الإيمان وأشرقت روحه بضياء الحب الخالص لله وخفقت جوانحه بالخوف والرهبة من عذاب الله وفهم الخطأ من الصواب ، مال بطبعه إلى تقبل الأخلاق الفاضلة ورفض كل خلق

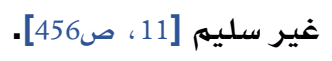

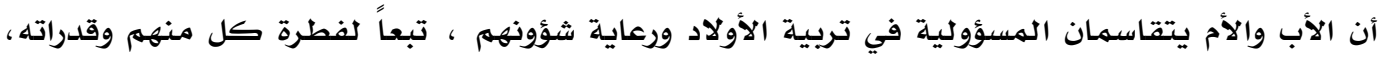
وكما يتولى الآباء رعاية الأولاد وتربيتهم وتعليمهان فأن الأخوة يشاركونهم في هذه المهمة العظيمة أيضاً ، إن العلاقات الإنسانية والاجتماعية التي يشاهدها الطفل داخل الأسرة يحاول تقليدها ومحاكاتهاتها وتبقى آثارها في نفسه بعد بلوغه واستقلاله عنها في أسرة جيدة ، إذ تتفاوت الأسرة في صلاحها وفسادها 
فأما أن تكون الأسرة صحيحة البناء يسودها الحب والألفة ، وتقدم علاقاتها على أساس التقوى وعبادة الله

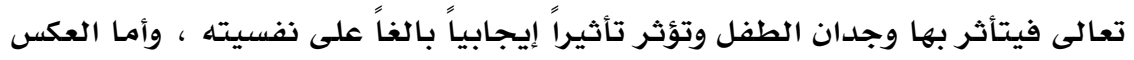

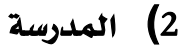

بعد أن ينهي الطفل طفولته المبكرة بين أحضان الأسرة ، يصبح في هذا الوقت أكبر نضجاً من قبل ، وأكثر قدرة على التعلم المنظم ، يأتي دور المدرسة التي يكتسب من رجالها المعارف والعلوم المختلفة لهنة التي تقدمها له من خلال المواد الدراسية والأنشطة اللاصفية والمدرسية المتعددة ، لذا فأن الوظيفة الرئيسية للمدرسة في نظر الإسلام هي تحقق التربية الإسلامية الصحيحة بأسسها الفكرية والعقائدية

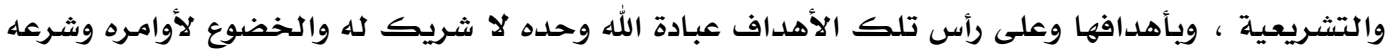

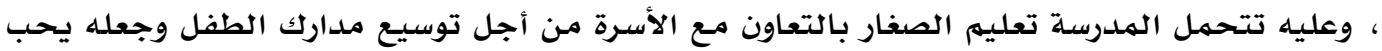

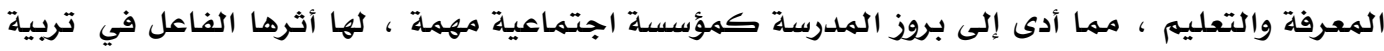
مختلف جوانب الطفل النفسية ، والاجتماعية والأخلاقية ، والسلوكية ، لاسيما وأن الطفل في السنوات التهات

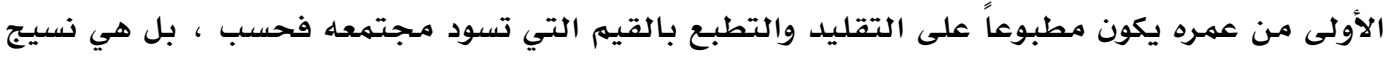

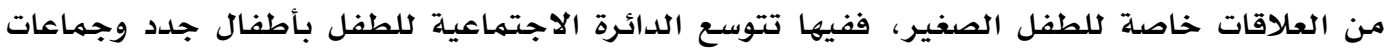
جديدة ، فيتعلم الطفل من جوها المزيد من المعايير الاجتماعية في شكل منظم ، كما يتعلم أدورا اجتماعية جديدة ، فهو يتعلهم الحقوق والواجبات ، وضبط الانفعالات ، والتوفيق بين حاجاته وحاجات

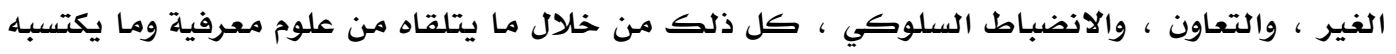
من مخالطة رفاقه في المدرسة ، فالمدرسة بالجملة لها أثرها الفعال في سلوك الأطفال وتوجهاتهم في

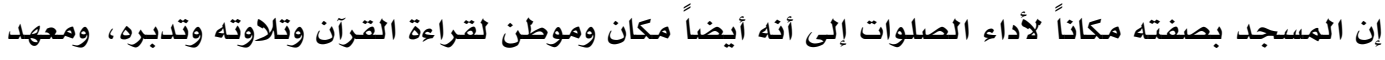

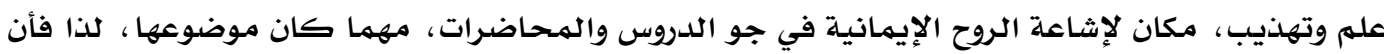

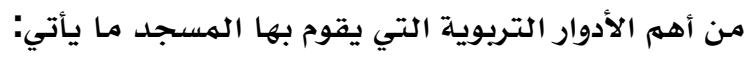

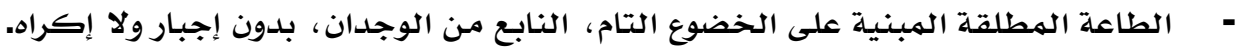
- التعود على النظام، فصلاة الجماعة تتطلب تسوية الصفوف والتقارب والتراص. - صلاة الجماعة تعلم المسلم التواضع، حيث الفقير بجانب الغني في خشوع.

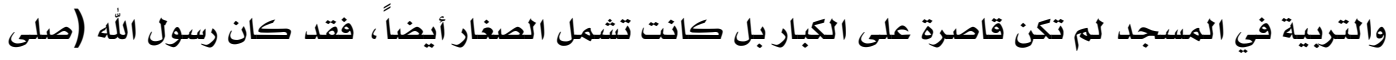

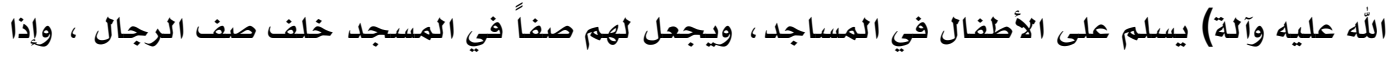

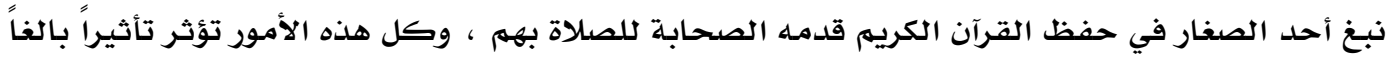

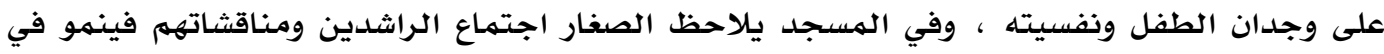

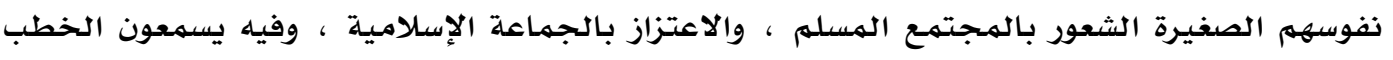
والمواعظ والدروس ، فيبدؤون بوعي العقيدة الإسلامية ، وفهم حقيقة وجودهم في الحياة ، والهدف من 
تتفاوت آثار وسائل الإعلام على الأفراد والجماعات والمجتمعات، ولها آثار مزدوجة على المجتمعح الإسلامي

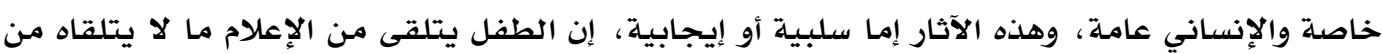
غيره، والتربية تحتل الوظيفة الأولى من وظائف الإعلام، لأنها الأساس في حياة الأفراد والجماعات

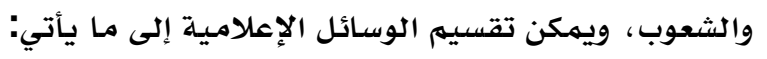

- الوسائل المطبوعة وتشمل الصحف والمجلات والدوريات والكتب والنشرات والكتيبات والكلافتات،

$$
\text { والملصقات. }
$$

- الوسائل السمعية وتشمل الصوتيات والإذاعات وغيرها من الوسـائل التي تعتمد على عنصـر الصوت. - الوسائل البهرية وتضهم هذه الوسائل المعارض والنصب التذذكارية، والأعلام واللافتات وغيرها من الوسائل التي تعتمدد على حاسة البصر. - الوسائل السمعية البصرية تضهم الوسائل التي تجمـع بين الصوت والصورة سواء كانت صورة صناعية أو طبيعية، من أمثالها العروض السينهمائية. - الوساكل الشفوية وتشمل الاتصال الشخصي المباشر بين شخص وآخر، أو الاتصال الجمعي بين

$$
\text { شخصين ومجمهوعة مـن الناس. }
$$

* الحاجات الوجدانية للطفل في الإسلام

قبل البدء في ذكر الحاجات الوجدانية للطفل لابد من معرفة مفهوم الحاجات وأنواعها ومن ثم بعض الحاجات الوجدانية للطفل. 1) مفهوم الحاجات الحاجة هي افتقار لشيء ما وإذا وجد حقق الإثباع والرضا والارتياح للكائن الحي ، والحاجـة شيء ضروري إما لاستقرار الحياة نفسها (حاجة فسيولوجية) أو لحياة بأسلوب أفضل

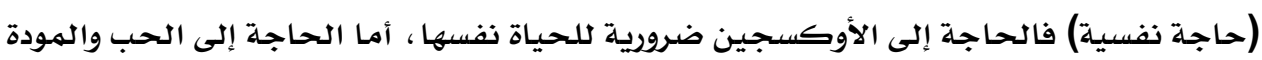
فهي ضرورية للحياة بأسلوب أفضل وبدون إثباعها يكون الفرد سيء التوافق ، وتتوقف كثير من خصائص الشخصية على حاجات الفرد ومدى إثباع هذه الحاجات ، لذا فأن فهم حاجات الفرد وطرق إثباعها يضيف إلى قدرتنا على مساعدته للوصول إلى أفضل مستوى للنمو النفسي والتوافق النفسي والصحسة النفسية [13]. 2) أنواع الحاجات للفرد حاجات معينة ينشأ عنها حوافز معينـة تؤدي بالفرد إلى محاولة الوصول لسد هذه الحاجات وفي المقابل الحرمان من إثباع الحاجات الفردية يؤدي إلى خلل في الاتزان

$$
\text { (أحمد، ، 1995م، ص17). ويمكن تقسيه هذه الحاجات إلى نوعين أساسين هما: }
$$

O ماجات النمو الجسمي والعقلي: فمن أمثلة الحاجات الجسمية الحاجة إلى الغذاء والحاجلة إلى النوم والراحلة، فالحاجلة إلى الملبس أو المسكن. أما مـن أمثلة الحاجـات العقلية فمنها الحاجة إلى البحث والاستطلاع، والحاجـة إلى تنمية المهارات العقلية، والحاجـة إلى اكتساب المهارة اللغوية. O ماجات النمو الوجداني والاجتماعي: ومن أمثلتها الحاجة إلى الحب والحاجـة إلى الأمن والطمأنينة، والحاجة إلى الرعاية والتوجيه، ، والحاجة إلى تقبل الذات والتقبل الاجتماعي، وكلها حاجات ضرورية يجب إشباعها على خير وجه ممكن حتى يتحقق 
j. port. sci. res.
ISSN: 2616-744

نمو شخصية الطفل نمواً سليماً متزناً. " ويشير(ماسلو) إلى أن ظهور تلك الحاجـات يعتهد على إثباع بعضها الآخر، وأن الحاجة التي تشبع تسيطر على الفرد وسلوكه بدرجـة تجعل نظرته إلى الحيـاة مختلفة وتؤثر تأثيراً بـالغاً في إدارته وبالتالي في سلوكه

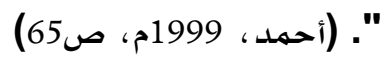

3) الحاجات الوجدانية للطفل الحاجة إلى الحب وهي من أهم الحاجات الوجدانية التي يسعى الطل

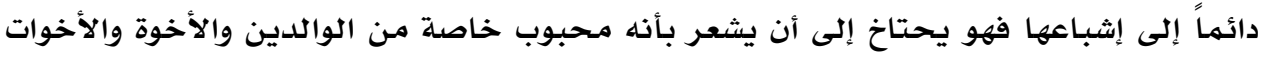

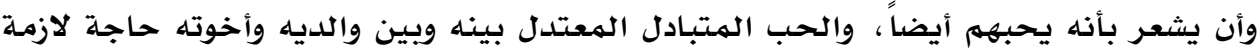
لصحته النفسية، أما الطفل الذي يعاني من ضعف الجانب العاطفي ويشعر أنه غير مرغوب فيه

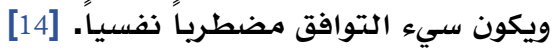
الحاجة إلى الأمن والطمأنينة يحتاخ الطفل طوال فترة طفولته إلى الشعور بالأمن وبأنه ينتمي

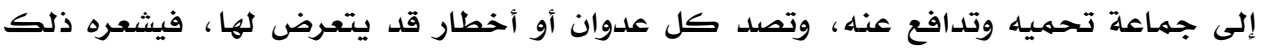

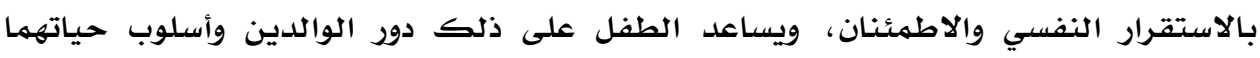
وعلاقتهما الأسرية التي يجب أن يسودها الاستقرار [15]. الحاجة إلى التقدير من أبعد الحاجات الوجدانية تأثيراً على الطفل الحاجة إلى التقدير، إثباعها يشعره بالقبول الاجتماعي لدى الآخرين واحترامهم وحبهم له فيزيد من علاقته بهم قوة، ومن ارتباطه بهم متانة، وإحباطها يشعره بعدم قبولهم له، ونبذهم إياه فينطوي على نفسه، وفتدان

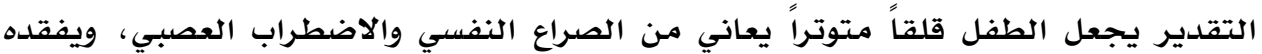
الإحساس بالمحبة والعطف. [16]. الحاجة إلى الاستقلال والاعتماد على النفس يحتاخ الطل في هذه المرحلة لأن يشعر بالحرية

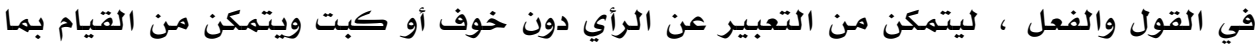
يرغب القيام به دون ضغط أو إحباط وفي إطار التوجيه الأبوي السليه ، ويحتاخ الطفل إلى الى الى الشعور بالمسؤولية وتحمل الأعباء الحياتية الأسرية المختلفة والاشتراك في القيام بالأعمال المنزلية ، وينمي عن طريق ذلك الثقة في الذات ويشعر بدوره وأهميته كفرد من أفراد الأسرة مما يضفي على شخصيته التكامل ويظللها بإطار من الثقة في الذات، والحرمان من ذلكئ يؤدي

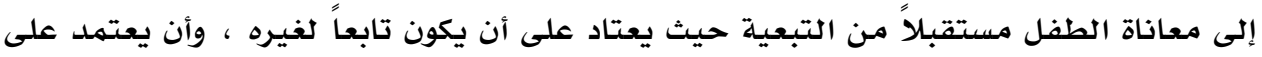

الآخرين ، وهذا ينقص من تكامل شخصيته ويهز كيانه أمام من يتعامل معهم .

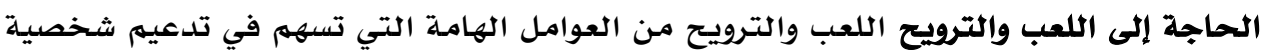

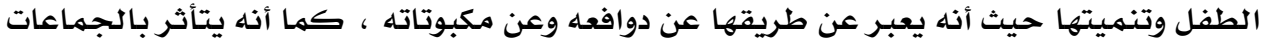

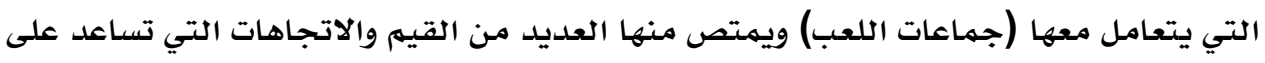

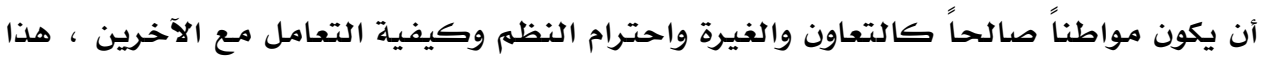
بجانب ما يحقق اللعب للطفل من تدعيم لبنائه الجسمي وزيادة قوته وحيويته ونشاطه وكيفية

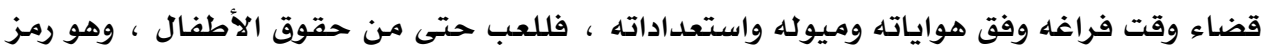

لحيويتهم ونشاطهم [17].

محمدد، أيسر مقبل. (2019). التربية الوجدانية للطفل في الإسلام. Journal Port Science Research، 2(2) ، 247- 


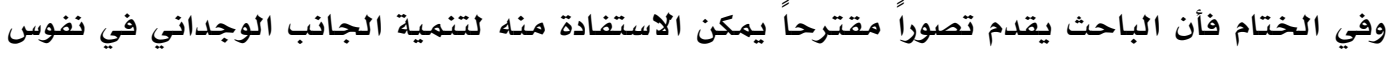

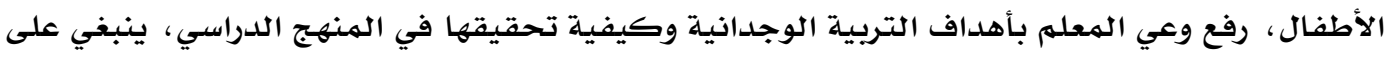

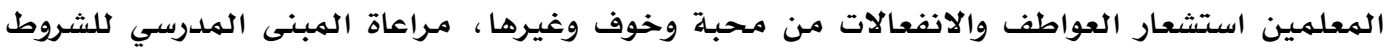

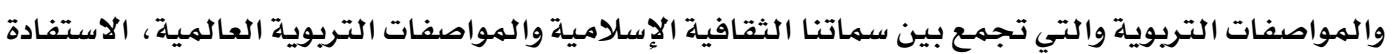
من المكتبة المدرسية لرفع مستوى الوعي بالذات لدى التلاميذ ، وإدارة الانفعالات وفهم النفعية من خلال تنمية المعرفة الوجدانية في إطار التعله داخل المكتبة، التركيز في طرائق التدريس على الأهداف التهي

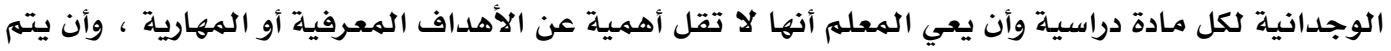
التركيز على محتوى ووسائل التربية الوجدانية .

\section{النتائج والتوصيات}

النتائج

توصل هذا البحث إلى بعض النتائج من أهمها ما يأتي:

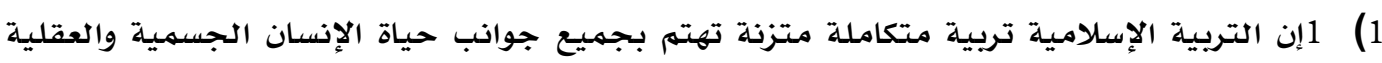
والروحية والاجتماعية والأخلاقية وكذلك الوجدانية منها والعاطفية. 2) إن مرحلة الطفولة لا تقل أهمية عن بقية مراحل حياة الإنسان بل ريما تكون أهم مرحلة لأن فيها

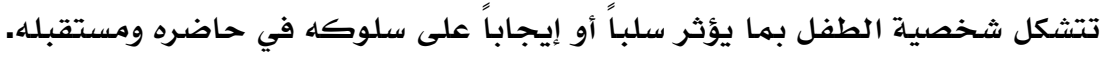
3) إن للطفل حاجات وجدانية يجب على الآباء والمربين والمعلمين إشباعها. 4) إن التربية الوجدانية كغيرها من جوانب التربية تمارس في المؤسسات التربوية وعلى رأسها الأسرة والمدرسة. 5) إن الاهتمام بأهداف التربية الوجدانية والمحتوى الدراسي الذي يحقق هذه الأهداف يساعد على تنمية الجانب الوجداني لدى أطفال المرحلة الابتدائية.

$$
\text { التوصيات: بابs }
$$

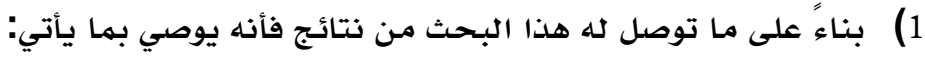

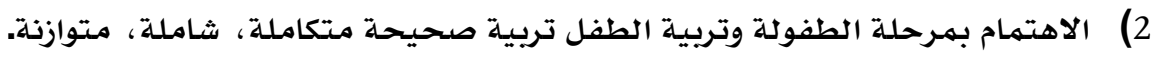

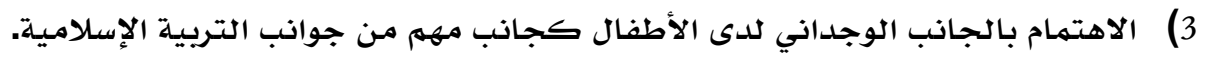

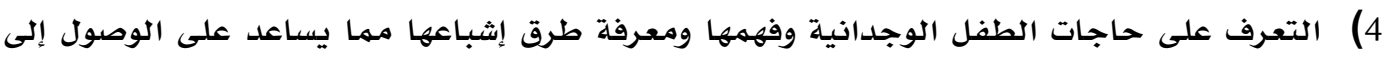
أفضل مستوى للنمو الوجداني والتوافق النفسي. 5) إعادة النظر في طرق التدريس المستخدمة واختيار أفضل الطرق وأعظمها أثراً في نفوس الأطفال.

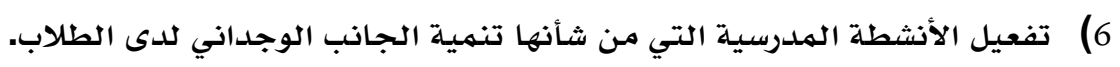


عبود ، محمد عبد الغني. (2006). أثرثقافة المجتمع في التربية الوجدانية للطفل. جامعة القاهرة،

(2) حجازي، سمية محمد علي. (1417هـ). التريية الوجدانية في الإسلام. رسالة دكتوراه غير منشورة، جامعة أم القرى، كلية التربية، مكلة المكرمة.

(3) مخيمر، هشام محمد. (1421هـ). علهم نفس النهو الطفولة والمراهقة، الرياض: اشبيليا للنشر النشرة والتوزيع. (4) ابن منظور، أبو الفضل، جمال الدين محمد بن مكرم. (711هـ). لسان العرب. (ط. 3). بيروت: دار

(5) الفقي، محمد سعد. (1390هـ). النفس أمراضها وعلاجها في التربية الإسلامية. القاهرة: مكتبة

(11) الجلال، عائشة عبد الرحمن. (1404هـ) المؤثرات السلبية في تربية الطفل المسلم وطرق علاجها. جدة: دار المجتمحع. (12) الخوالدة، ناصر أحمد، عيد، يحيى إسماعيل. (2005). مراعاة مبادئ الفروق الفردية وتطبيقاتها

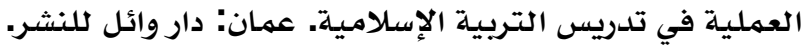

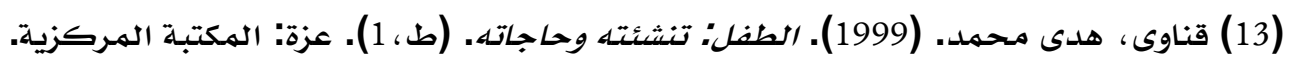

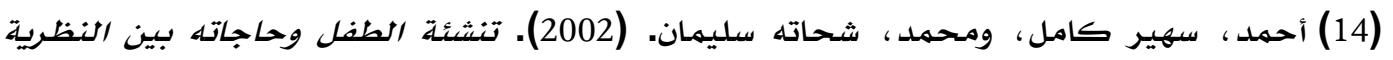
والتطبيق. الإسكندرية: مركز الإسكندرية للكتاب.

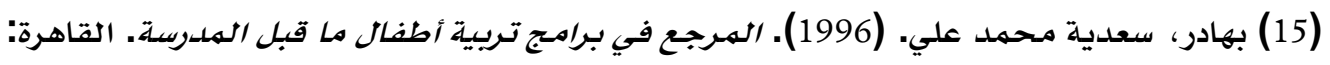
مكتبة الصور لخدمات النشر.

(16) الزنتاني، عبد الحميد الصيد. (1984). أسس التربية الإسلامية في السنة النبوية. تونس: الدار العربية للكتاب. (17) الجقندي، عبد السلام عبد الله. (1424هـ) التربية المتكاملة للطفل المسله في البيت والمدرسة. دمشق: دار قتيبة. 